Research Paper

\title{
Cellular and Phenotypic Characterization of Canine Osteosarcoma Cell Lines
}

\author{
Marie E. Legare, Jamie Bush, Amanda K. Ashley, Taka Kato and William H. Hanneman ${ }^{凶}$ \\ The Center for Environmental Medicine, Department of Environmental and Radiological Health Sciences, College of Veter- \\ inary Medicine and Biomedical Sciences, Colorado State University, Fort Collins, CO 80523, USA
}

Corresponding author: William H. Hanneman, Ph.D., Director - Center for Environmental Medicine, College of Veterinary Medicine and Biomedical Sciences, Fort Collins, Colorado 80523-1680, Phone: (970) 491-7043, Fax: (970) 491-7569, E-mail: william.hanneman@colostate.edu

(C) Ivyspring International Publisher. This is an open-access article distributed under the terms of the Creative Commons License (http://creativecommons.org/ licenses/by-nc-nd/3.0/). Reproduction is permitted for personal, noncommercial use, provided that the article is in whole, unmodified, and properly cited.

Received: 2010.11.16; Accepted: 2011.04.28; Published: 2011.05.04

\begin{abstract}
Canine and human osteosarcoma (OSA) have many similarities, with the majority of reported cases occurring in the appendicular skeleton, gender predominance noted, high rate of metastasis at the time of presentation, and a lack of known etiology for this devastating disease. Due to poor understanding of the molecular mechanisms underlying OSA, we have characterized seven different OSA canine cell lines: Abrams, D I7, Grey, Hughes, Ingles, Jarques, and Marisco and compared them to U2, a human OSA cell line, for the following parameters: morphology, growth, contact inhibition, migrational tendencies, alkaline phosphatase staining, heterologous tumor growth, double-strand DNA breaks, and oxidative damage. All results demonstrated the positive characteristics of the Abrams cell line for use in future studies of OSA. Of particular interest, the robust growth of a subcutaneous tumor and rapid pulmonary metastasis of the Abrams cell line in an immunocompromised mouse shows incredible potential for the future use of Abrams as a canine OSA model. Further investigations utilizing a canine cell model of OSA, such as Abrams, will be invaluable to understanding the molecular events underlying OSA, pharmaceutical inhibition of metastasis, and eventual prevention of this devastating disease.
\end{abstract}

Key words: Abrams, Canine, Osteosarcoma, U2

\section{Introduction}

Osteosarcoma (OSA) is a deadly form of musculoskeletal cancer which develops from the cells responsible for forming the bone matrix. ${ }^{22}$ In children and adolescents, OSA is the most common type of primary bone cancer, ${ }^{5,23}$ with approximately 1-3 cases per million annually, and $70-75 \%$ of patients being 10 to 25 years of age.12,19 Interestingly, the incidence of OSA is slightly higher in males than females, with a ratio of 1.5:1.19,23 Factors underlying the development of OSA are still largely unknown, however humans are at a higher risk following periods of rapid adolescent growth, with the metaphyseal area adjacent to the growth plate of long bones most commonly af- fected. ${ }^{19,23}$ Most OSA start as solitary lesions, especially within the distal femur, proximal tibia, and proximal humerus. ${ }^{22}$ Although micrometastatic disease is likely present in approximately $80 \%$ of human patients, it is only detected in $8-15 \%, 7,8$ and as a result patients often die from pulmonary metastatic disease. ${ }^{5,22}$

In canines, OSA is more common than it is in humans, with approximately 10,000 new cases each year. ${ }^{3}$ OSA is generally a disease of large breed canines where increasing height is a more prominent risk factor then body weight. ${ }^{18}$ As in humans, males more commonly present with OSA than females,, 10 
although some studies reveal no prevalence between sexes. ${ }^{1}$ When a dog presents with OSA, less then $10 \%$ of the cases have radiographic evidence of lung metastasis. ${ }^{22}$ Canine OSA is most often found in the appendicular skeleton, $, 5,8,24$ originates in the metaphyseal region of the long bones (similar to humans), and occurs twice as frequently in the thoracic versus the pelvic limbs. The most common site of canine OSA is the distal radius followed by the proximal humerus. 5,18 Despite treatment with amputation and chemotherapy, over $80 \%$ of dogs succumb to metastatic disease within 2 years of diagnosis.., 24

To summarize, many commonalities between human and canine OSA exist: the long bones are most often affected, males are affected more commonly than females, the etiology is unknown, and very few cases show lung metastasis at the time of presentation. Because of these similarities, the characterization and use of a canine model of OSA could be invaluable in understanding this devastating disease, aiding in assessing potential therapeutic agents and potentially preventing disease formation. In this report, we have characterized six canine OSA cell lines for morphology, growth, contact inhibition, migrational tendencies, alkaline phosphatase protein, heterologous tumor growth, double-strand DNA breaks, and oxidative damage and compared them to U2, a human OSA cell line. Further investigations utilizing a canine cell model of OSA with xenograft potential will be invaluable to understanding the cellular and molecular events underlying OSA.

\section{Materials and Methods}

Cell Culture: Canine OSA cell lines Abrams, D17, Grey, Hughes, Ingles, Jarques, and Marisco were a generous gift from Dr. Greg MacEwan, University of Wisconsin, Madison, Wisconsin. The human cell line U2, was purchased from ATCC. All OSA cell lines were grown in Modified Eagles Medium (MEM; Cellgro $^{\mathrm{TM}}$ ) supplemented with $15 \%$ fetal bovine serum (FBS; HyClone ${ }^{\mathrm{TM}}$ ), 2\% MEM vitamins, and 1\% each L-glutamine, non-essential amino acids, and sodium pyruvate. All cells were maintained at $37^{\circ} \mathrm{C}$, humidified with $5 \% \mathrm{CO}_{2}$

Cell Proliferation: Abrams, D17, Grey, Hughes, Ingles, Jarques, and U2 were used in this experiment. In order to determine the varying proliferation rates of the cell line(s), a seven-day proliferation trial was performed. To take into account differences in cell size, as some OSA cells were quite large and spindloid in comparison to other cell lines, cells were harvested at the onset of this experiment when flasks reached $90 \%$ confluency and then each cell line was diluted similarly before being added to the $100 \mathrm{~mm}^{2}$ plates.
Thus, each $75 \mathrm{~cm}^{2}$ flask was trypsinized when cells were $90 \%$ confluent with $1 \mathrm{ml} 0.25 \%$ trypsin-EDTA $0.25 \%$ for 5 min. MEM with $15 \%$ FBS (22 mL total volume) was added to each flask and the cells were thoroughly mixed. One $\mathrm{mL}$ of this suspension was removed and cells were counted to establish the count at day 0 . One $\mathrm{mL}$ aliquots of the remaining $21 \mathrm{~mL}$ were added to $9 \mathrm{~mL}$ of MEM with 15\% FBS in 100 $\mathrm{mm}^{2}$ plates. Cell counts were performed daily (22- 24 $\mathrm{h}$ intervals) as follows: 3 plates from each cell line were trypsinized with $0.5 \mathrm{~mL} 0.25 \%$ trypsin-EDTA for $5 \mathrm{~min}, 3 \mathrm{~mL}$ MEM with 15\% FBS was added, and all 3 dishes were combined and thoroughly mixed. Each sample was diluted $1: 10$ with $0.4 \%$ PBS and $37 \%$ formaldehyde solution and counted twice. This resulted in the number of cells/mL using the following calculation: [(value from counter \#1) + (value from counter \#2)] X $10=$ cells $/ \mathrm{mL}$. In order to standardize the cell count data the cell number of subsequent days was divided by the number of cells counted on day zero. Counting was performed using a Particle Data Counter (El Zone 180 Particle Data, Inc) and double-checked using a hemocytometer. The experiment was performed in triplicate for each cell line for $7 \mathrm{~d}$.

Growth in Soft Agar: Abrams, D17, Grey, Hughes, Ingles, and U2 were used for this experiment based on their performance in the cell proliferation experiment above. Agar (Gibco ${ }^{\mathrm{TM}}$ ) was reconstituted with $100 \mathrm{~mL}$ MEM with $15 \%$ FBS to $0.3 \%$ and $0.8 \%$ final concentration, boiled for $1 \mathrm{~min}$ and autoclaved. The agar was cooled slightly, then $100 \mathrm{~mL}$ of agar was mixed with $2.5 \times 10^{5}$ cells in 5 mL MEM with $15 \%$ FBS. Each cell-agar mixture $(5 \mathrm{~mL})$ was added to a $100 \mathrm{~mm}^{2}$ dish. Each experiment was performed in duplicate. The plates were visualized at $4 x$ daily and colony measurements were taken and photographed on $4 \mathrm{X}$ power at $8 \mathrm{~d}, 10 \mathrm{~d}, 11 \mathrm{~d}, 15 \mathrm{~d}, 18 \mathrm{~d}$ and $22 \mathrm{~d}$ post-plating. Images were acquired using a Zeiss Axiovert $200 \mathrm{M}$ microscope equipped with a $63 \mathrm{X} 1.4 \mathrm{~N} / \mathrm{A}$ oil immersion objective and Hammatsu ORCA-ER cooled charge-coupled device camera.

Boyden Chamber Assay: Abrams and U2 were assessed in this experiment due to the strong performance of Abrams in the cell proliferation and colony growth experiments. Ingles was also used as a poor growth control cell line (data not shown). The cell lines were grown to $80 \%$ confluency and FBS starved for $24 \mathrm{~h}$ prior to harvesting. Cultures were harvested and volume adjusted to yield $2.5 \times 10^{6}$ cells $/ \mathrm{mL}$. Cells suspended in either serum-free growth medium (300 $\mu \mathrm{L})$ or normal growth medium $(300 \mu \mathrm{L})$ with were added to the appropriate wells (fibronectin- or BSA-coated) of the Boyden chambers under sterile conditions, as per manufacturers instructions. The 
cells were incubated for $24 \mathrm{~h}$ and 6 drops of Cell Stain Solution were added to each well after removal of media. The fibronectin-coated Boyden chambers from the test plate were carefully removed and the cells were removed from inside the chamber. Boyden chambers were then placed in the test plate wells with stain (from above). The same procedure was followed for the BSA-coated control chambers and they were placed in the control wells with stain. Plates were then incubated at room temp for $30 \mathrm{~min}$. Cell stain was removed and the wells were washed with PBS. Extraction buffer $(300 \mu \mathrm{L})$ was added to the empty wells in the test and control plates. Boyden chambers were washed thoroughly with distilled water, cleaned and placed into extraction buffer in their respective plates. Plates were gently shaken to elute stain for 10 min, and then $100 \mu \mathrm{L}$ of stained solution was transferred from the elution wells into a microtiter plate. Absorbance at $540 \mathrm{~nm}$ was analyzed.

Heterologous Tumor Growth and Metastasis: Abrams, Ingles, and U2 were used for this experiment. Rag1 male mice were purchased from the Jackson Laboratory, and acclimated in Colorado State University's central animal care facility, which is fully accredited by the American Association for Accreditation for Laboratory Animal Care. All animal procedures were conducted following an Animal Care and Use Research Protocol approved by the Colorado State University Animal Care and Use Committee. Mice were allowed ad libitum access to food and water throughout the duration of experimentation. $8 \mathrm{wk}$ old mice were injected subcutaneously mid-dorsally with $1 \times 10^{6}$ cells suspended in $0.2 \mathrm{~mL}$ PBS, and monitored daily for tumor growth. At $10 \mathrm{wk}$ post-injection, a MRI was performed on each mouse to determine possible lung metastasis. Mice were then euthanized, necropsied, and tissues submitted for histopathologic examination.

Alkaline Phosphatase Staining: Abrams, D17, Grey, Hughes, Ingles, Jarques, and U2 were evaluated for expression of alkaline phosphatase and fibroblasts were used as negative controls. Chamber slides were fixed for $10 \mathrm{~min}$ in $1 \%$ paraformaldehyde and air-dried. Slides were rehydrated in buffer $(100 \mathrm{mM}$ Tris- $\mathrm{HCl}, 100 \mathrm{mM} \mathrm{NaCl}$ and $50 \mathrm{mM} \mathrm{MgCl}_{2}$ ), washed in TBS with $0.05 \%$ TBS (TBS-T0.5) and coated with DI water to keep moist. For staining, 100 $\mu 1 \mathrm{BCIP} / \mathrm{NBT}$, prepared as instructed in kit (Vector Laboratories, SK-5400) was added to each reservoir without introducing bubbles and slides were allowed to sit covered and in the dark for $1 \mathrm{~h}$. The slides were rinsed with TBS-T0.5 and another $100 \mu \mathrm{BCIP} / \mathrm{NBT}$ was added to each reservoir. The slides were incubated overnight and $100 \mu \mathrm{BCIP} / \mathrm{NBT}$ was added to each reservoir, allowed to sit for $1 \mathrm{~h}$ and rinsed with TBS-T0.5. The slides were then counterstained with hematoxylin for $30 \mathrm{~s}$ and coverslipped with Kaiser's aqueous mounting media.

Phosphorylated H2AX Immunocytochemistry: Cells were cultured for $24 \mathrm{~h}$ on plastic chamber slides and then washed with PBS followed by fixation with $4 \%$ paraformaldehyde for 15 minutes. Following a second wash with PBS, cells were then permeabilized with $0.2 \%$ Triton $X$ with PBS for 10 minutes. Cells were then covered with parafilm and incubated with $10 \%$ goat serum with PBS overnight at $4^{\circ} \mathrm{C}$. Following overnight incubation, the cells were then covered with parafilm and incubated with a mouse monoclonal phosphorylated histone H2AX (Ser139) (Millipore) in $10 \%$ goat serum with PBS for 1 hour at $37^{\circ} \mathrm{C}$. The cells were then washed three times for 10 minutes each in PBS, followed by a 1-hour incubation at $37^{\circ} \mathrm{C}$ with the appropriate secondary antibody. The slides were then washed three times for 10 minutes each in PBS, and then counter stained with Vectashield mounting media with DAPI. The cells were cover slipped and visualized with Olympus AX70 equipped with a cooled CCD Sensys camera. MacProbe was utilized to obtain images.

Oxidative Damage: Cells were cultured for $24 \mathrm{~h}$ on plastic chamber slides and then washed with PBS followed by fixation with $4 \%$ paraformaldehyde for 15 minutes. Following a second wash with PBS, cells were then permeabilized with $0.2 \%$ Triton $X$ with PBS for 10 minutes. Cells were then covered with parafilm and incubated with $10 \%$ goat serum with PBS overnight at $4^{\circ} \mathrm{C}$. Following overnight incubation, the cells were then covered with parafilm and incubated with a FITC-8-oxoguanine protein conjugate (Kamiya Biomedical Company) in 10\% goat serum with PBS for 1 hour at $37^{\circ} \mathrm{C}$. The cells were then washed three times for 10 minutes each in PBS and counter stained with Vectashield mounting media with DAPI. The cell is cover slipped and visualized with Olympus AX70 equipped with a cooled CCD Sensys camera. MacProbe was utilized to obtain images.

Statistical Methods: Analysis of variance was used to determine statistical significance with GraphPad Prism software. When statistical differences were detected, Tukey's post hoc test was used to determine individual variations. As the $\mathrm{U} 2$ cell line is currently employed most commonly and the purpose of these experiments is identifying whether a comparable canine cell line exists, all means were compared to U2.

\section{Results}

During the 7-day testing period, the cell lines 
were vastly different in their proliferation characteristics (Fig. 1). Overall cellular proliferation demonstrates that at day 7 the Abrams line was an aggressively growing OSA cell line, as it neither died off nor reached a plateau. Additionally, the Abrams line quickly grew colonies in soft agar, an indicator of anchorage-independent growth, and produced one of the highest colony diameters, $2768.9 \mu \mathrm{m}$ over the 22 day testing period (data not shown). In comparison, maximal diameters for the other cells lines were as follows: $2339.3 \mu \mathrm{m}$ for D17, $1301.6 \mu \mathrm{m}$ for U2, and $529.3 \mu \mathrm{m}$ for Ingles. Ingles in addition to having minimal soft agar colony growth over the 22 day period was also one of the slower proliferators, to the point where the data needed to be represented on a different Y-axis in order to be visualized (Fig 1). The cell lines Grey and Hughes were suicidal early in the cell proliferation assay, dying by day 4 in the assay (data not shown), and had the smallest colony growth in soft agar after 22 days ( $529 \mu \mathrm{m}$ maximal diameter for both of these lines). Additionally, Jarques also grew poorly in the proliferation assay (data not

U2

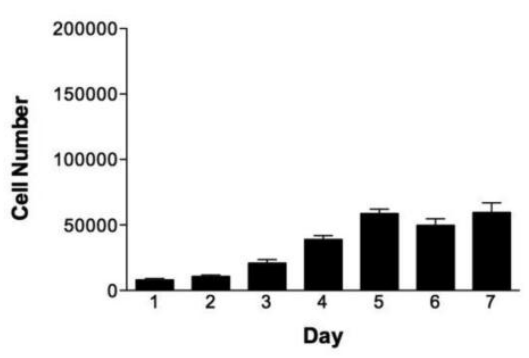

D 17

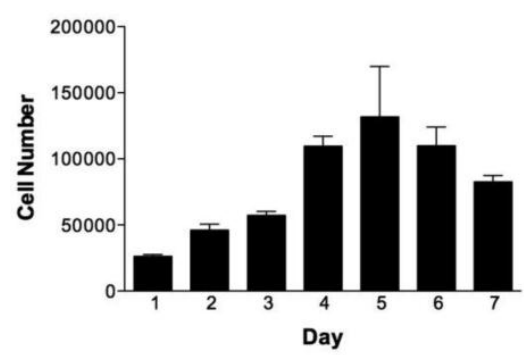

shown as it was lower than Ingles), was difficult to maintain in culture and did not grow in the soft agar. Thus, as we were looking for a cell line that would model canine osteosarcoma over usage of the human U2 cell line, Grey, Hughes and Jarques were not carried further in the Boyden Chamber assay nor the xenografting experiment.

The migrational capacity of cells is indicative of metastatic potential. Boyden chamber wells were coated with FN to assess migration or BSA as a negative control. Abrams demonstrated significant migrational tendencies compared to the BSA negative controls (Fig. 2) and performed significantly better than $\mathrm{U} 2$ in this assay. Ingles, as the negative or poor growth control demonstrated no migrational tendencies (data not shown). Furthermore, the Abrams cells consistently stained positive for alkaline phosphatase (Fig. 3-4) with all other cell lines having a poor and inconsistent staining pattern. Based upon these results, Abrams was selected as an aggressive OSA line comparable to U2.
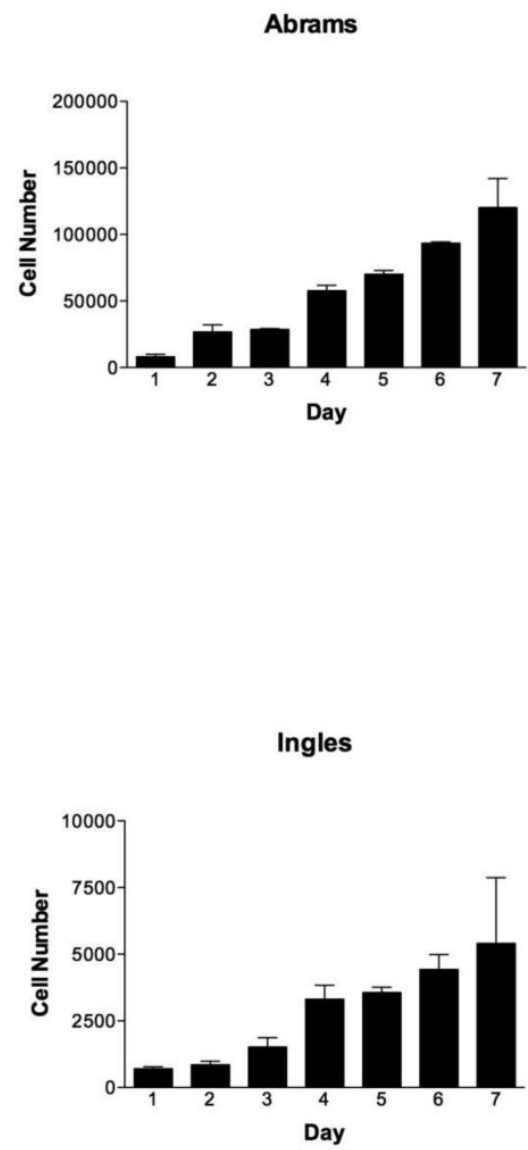

Figure I. OSA cell lines proliferate differently over time, with the Abrams cell line outperforming U2. Cell numbers per cell line (U2, Abrams, DI7 and Ingles represented) over the 7 day experimental period. Please note that the cell numbers (on the $Y$ axis) spans 0-200,000 cells for all cell lines except the Ingles which proliferated so slowly that the Y-axis spans 0-I,000 in order to visualize the data for this cell line. Error bars represent standard deviation. 


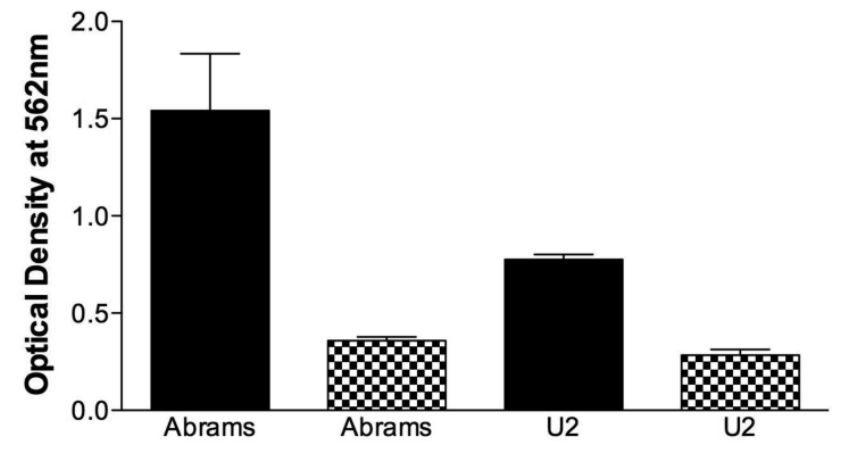

Figure 2. Abrams cells migrate more extensively than $\mathbf{U} 2$ cells in the Boyden chamber. Chamber wells were coated with fironectin (Black Bars) or bovine serum albumin (Checkered Bars), and 750,000 cells were added to each well. After $24 \mathrm{~h}$ cells were stained, lysed, and optical density at $540 \mathrm{~nm}$ was read. Statistical differences were determined via two-way analysis of variance, with cell type $(p=0.003)$ and coating $(p<0.00 \mathrm{l})$ being significant, as well as the cell type and coating interaction $(p=0.0086)$.

Subcutaneous injection of Abrams cells resulted in tumor growth in the skin with lung metastases 10 wks post-injection (Fig. 3). These tumors were grossly evident in the skin and could be identified grossly as suspicious areas within the lung tissue and histopathologically in both the skin and lung. However, use of MRI at 10 weeks was not sensitive enough to declare metastasis and only after going back to the images after gross and histological examination could the areas be characterized as suspicious on MRI scan. Other internal organs were examined grossly and histopathologically and did not contain evidence of metastases. Subcutaneous injections of Ingles or U2 cells did not result in tumor growth in the skin nor metastasis to lungs or other organs.

$\gamma \mathrm{H} 2 \mathrm{AX}$ immunocytochemistry demonstrated that the biologically more aggressive canine and human OSA cell lines (Abrams, D17, Grey, Hughes, Marisco, and U2) demonstrated more nuclear foci of phosphorylated $\gamma \mathrm{H} 2 \mathrm{AX}$ as compared to the less aggressive canine OSA cell lines (Ingles and Jarques) (Fig. 4).

Additionally, the biologically more aggressive canine OSA cell lines (Abrams, D17, Grey, and Marisco) demonstrate increased oxidative damage as evidenced by increased mitochondrial and nuclear staining of 8-oxoguanine. The canine OSA cell line Hughes demonstrates intermediate staining, while the less aggressive canine OSA cell lines (Ingles and Jarques) and the human OSA cell line (U2) demonstrate minimal staining (Fig. 5).

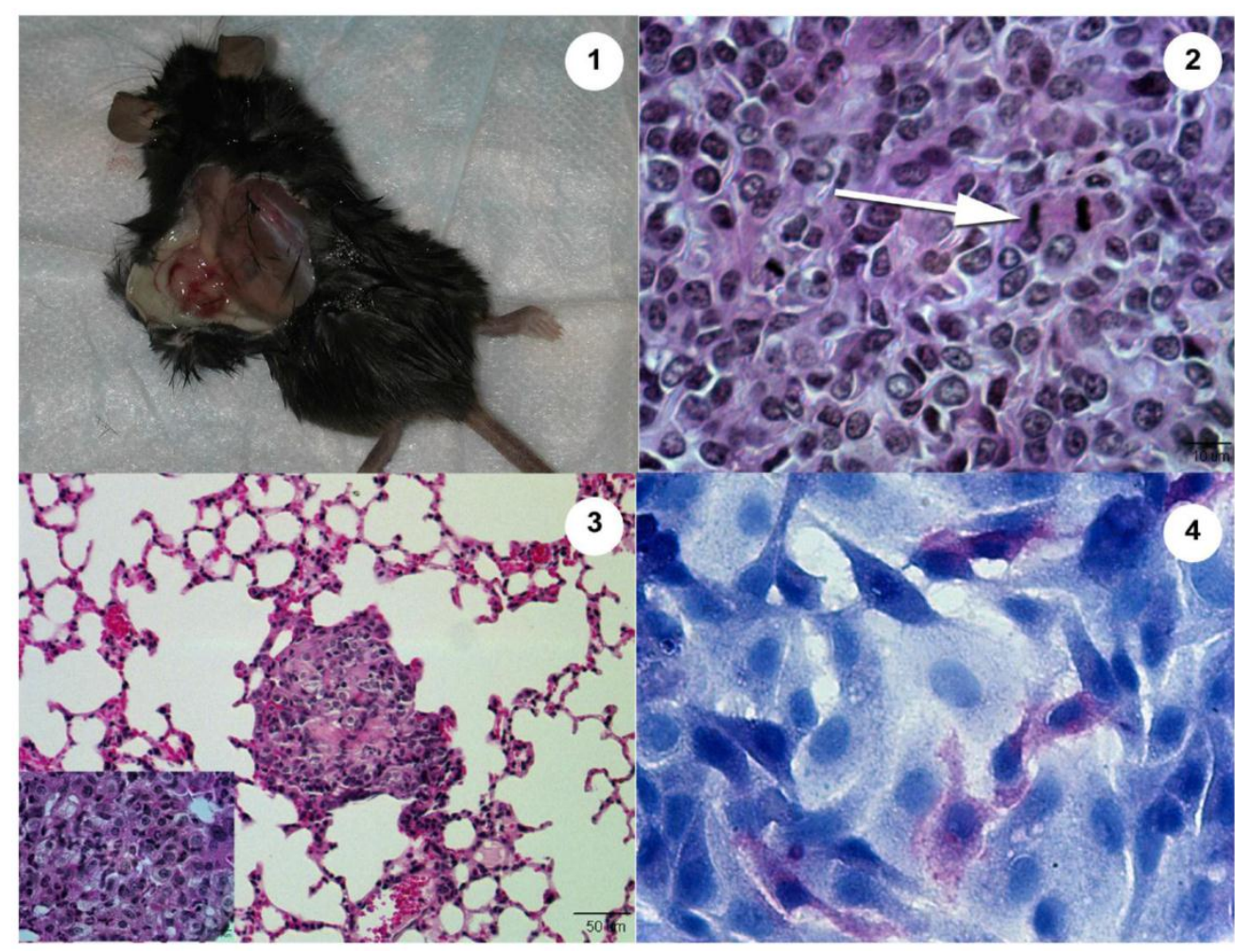

Figure 3. The Abrams OSA cell line produces an aggressive tumor in the Rag I mouse. I. Heterologous tumor growth of Abrams cells in Ragl mouse. Grossly, the tumor measures $13.4 \mathrm{~mm}$ long $\times 8.8 \mathrm{~mm}$ wide 10 wk post injection. 2. Histopathology of heterologous Abrams skin tumor 10 wk post xenografting via subcutaneous injection (Hematoxylin and Eosin). Arrow denotes a mitotic figure. 3. Heterologous Abrams cell tumor metastasis to lung (Hematoxylin and Eosin). Inset of lung metastasis at higher power. 4. Abrams cells stain positively for alkaline phosphatase with hematoxylin counterstain. 


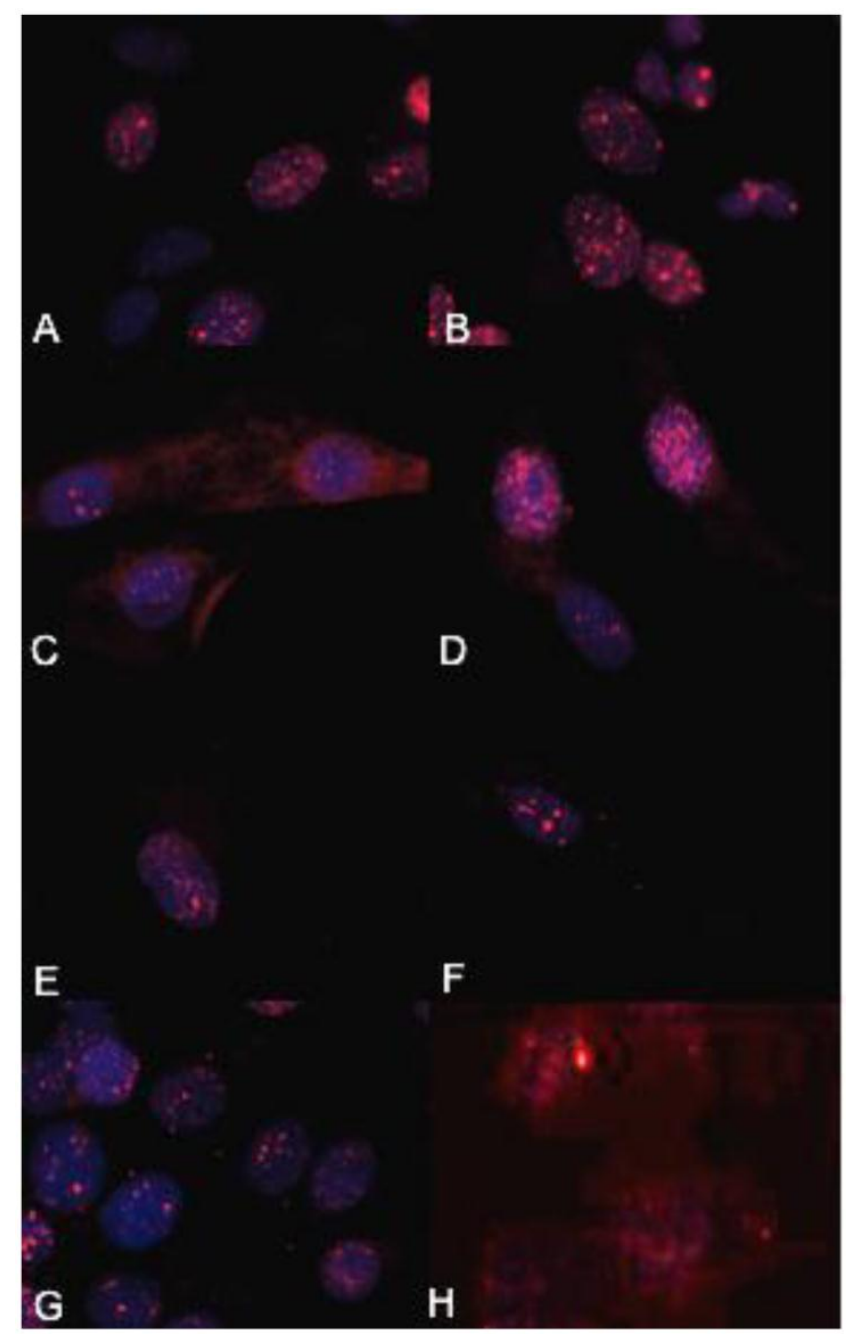

Figure 4. The biologically more-aggressive OSA cell lines demonstrate increased double-strand DNA damage. In all cell types nuclear phosphorylated H2AX foci are stained red with DAPI counterstain. $\gamma \mathrm{H} 2 \mathrm{AX}$ immunocytochemistry demonstrates that Abrams, D I7, Grey, Hughes, and U2 exhibit more nuclear foci of phosphorylated $\gamma \mathrm{H} 2 \mathrm{AX}$ as compared to intermediate staining within Marisco and the less aggressive canine OSA cell lines (Ingles and Jarques). U2 cells have the highest level of nuclear HSAX staining compared to all other cell lines. Representative images from the following osteosarcoma cell lines are within the panels indicated: A) Abrams, B) DI7, C) Grey, D) Hughes, E) Ingles, F) Jarques, G) Marisco, H) U2.

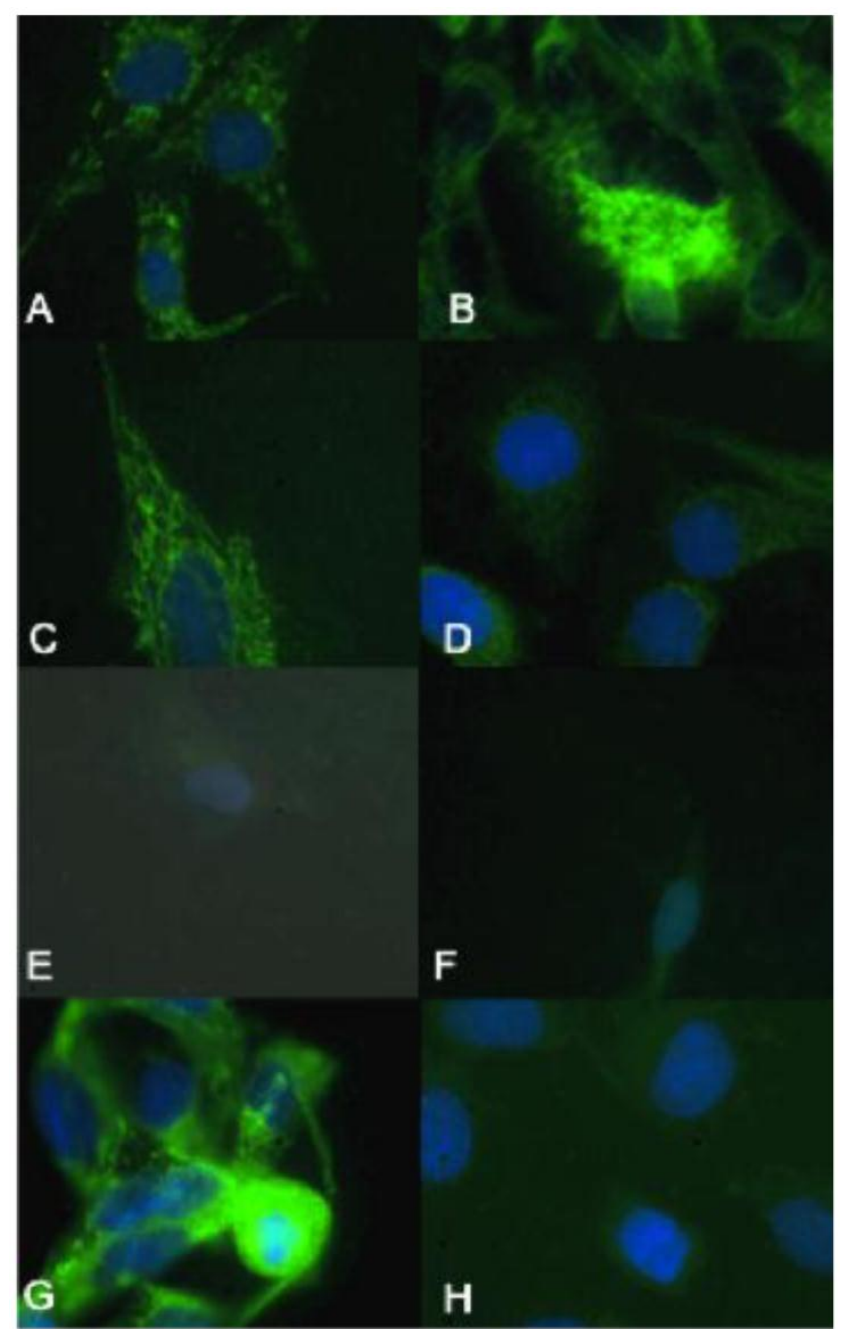

Figure 5. The biologically more-aggressive OSA cell lines demonstrate increased mitochondrial and nuclear oxidative evidence characterized by increased DNA 8-oxoguanine. In all cell types mitochondrial and nuclear 8-oxoguanine foci are stained green with DAPI for nuclear counterstain. Abrams, DI7, Grey, and Marisco demonstrate increased oxidative damage as evidenced by increased mitochondrial and nuclear staining of 8-oxoguanine. Hughes demonstrates intermediate staining, while the less aggressive canine OSA cell lines (Ingles and Jarques) and the human OSA cell line (U2) demonstrate minimal staining of 8-oxoguanine. Representative images from the following osteosarcoma cell lines are within the panels indicated: A) Abrams, B) DI7, C) Grey, D) Hughes, E) Ingles, F) Jarque, G) Marisco, H) U2. 


\section{Discussion}

Although many common characteristics exist between human and canine OSA, the underlying etiology of the disease is poorly understood in either species. Initial genetic characterization of a few human and canine OSA cell lines have indicated mutations in PTEN16, inactivation of p5315 and overexpression of met and sis oncogenes ${ }^{6,17}$ to be of importance in these tumors. Further characterization of canine OSA cell lines will provide information with which to select an appropriate in vitro model to aid in identifying molecular and/or genetic mechanisms underlying this devastating tumor, as well as provide an experimental platform to test potential therapeutic interventions. Based upon our results, the canine osteosarcoma Abrams cell line could indeed be utilized as such, as these cells possess more characteristics indicative of metastatic OSA compared to the human cell line currently employed, U2.

Of all lines tested, Abrams continued its rapid proliferation without dying off, indicative of an aggressive and continuously growing phenotype. Further, the Abrams cells showed significant differences in migration potential. Additionally, the Abrams cell line produced large colonies in soft agar, indicating capability of anchorage-independent growth with little contact inhibition, indicative of carcinogenesis and metastatic potential. Only the Abrams cells consistently stained positively for alkaline phosphatase, an enzyme used to differentiate OSA from other soft tissue tumors on histopathology, and one that is often used to correlate with prognosis in OSA patients.7,11,20,21 In some studies, elevated serum levels of alkaline phosphatase are correlated with approximately $50 \%$ shorter survival times despite assertive treatment. 7,11,19

Previous experiments correlate significant cell migration in a Boyden chamber with increased invasive properties in vivo. ${ }^{4}$ The Abrams cells migrated extensively, demonstrating a high potential to be invasive in vivo, surpassing even the migrational capacity of the human U2 line. Following subcutaneous injection into Rag1 mice, only the Abrams cell line formed subcutaneous tumors at the site of injection and metastasized to lung tissue. Fitzpatrick et al. demonstrated that the D17 cell line could be utilized as a xenograft, but there was no indication of metastasis (9). Moreover, Kanaya et al. utilized the POS cell line in their studies of the anti-tumor effect of adenoviral-vector mediated p53 gene transfers in nude mice but there again was no indication of metastasis after POS xenograft formation in these mice. ${ }^{13}$ As tumor development and subsequent formation of metastases are hallmark characteristics of OSA, the Abrams cell line proved to be a good choice for a model of OSA metastasis. Osteoid was not easily detectable in histopathologic sections of the skin or lung tumor sites, though it is considered to be a histological indicator of OSA. However, minimal or non-detectable osteoid may be secreted in poorly to undifferentiated OSA and thus not be identified on routine histological section. Moreover, additional characteristics of neoplasia were noted including open nuclei, frequent mitotic figures, anisokaryosis, and anisocytosis (Fig. 3).

Carcinogenesis in general is associated with DNA replication stress and oxidative damage, resulting in DNA double-strand breaks, genomic instability, and selective pressure for p53 mutations. DNA double strand breaks result in massive relaxation of chromatin coiling. ${ }^{14}$ Misrepaired or unrepaired DNA double strand breaks contributes to chromosomal aberrations leading to cell death, mutation, and oncogenic transformation. ${ }^{14} \mathrm{H} 2 \mathrm{AX}$ is a member of the histone H2A family and is involved in nucleosomal organization of chromatin. ${ }^{2}$ The basic subunit of chromatin, the nucleosome, consists of a core of eight proteins, two from each of the $\mathrm{H} 2 \mathrm{~A}, \mathrm{H} 2 \mathrm{~B}, \mathrm{H} 3$, and $\mathrm{H} 4$ families, with about $140 \mathrm{bp}$ of DNA coiled around the core and the fifth histone family, H1, on the linker DNA acting as a bridge between adjacent nucleosomes. ${ }^{2}$ Each nucleosome contains two H2A molecules and $\mathrm{H} 2 \mathrm{AX}$ is synthesized in a replication-dependent and replication-independent manner. ${ }^{2}$ Upon double-strand break formation, members of the PI3K-like kinase family, including ataxia telangiectasia mutated (ATM), ataxia telangiectasia and Rad3-related (ATR), and DNA-dependent protein kinase (DNA-PK), are activated and phosphorylate H2AX and other DNA repair and checkpoint proteins. ${ }^{2}$ As double-strand DNA breaks are repaired, $\gamma \mathrm{H} 2 \mathrm{AX}$ foci disappear. ${ }^{2}$ There are two potential mechanisms of $\gamma \mathrm{H} 2 \mathrm{AX}$ removal: dephosphorylation of $\gamma \mathrm{H} 2 \mathrm{AX}$ or removal of phosphorylated $\gamma \mathrm{H} 2 \mathrm{AX}$ from the chromatin. ${ }^{2}$ Dephosphorylation depends upon the phosphatases PP2A and PP4C. Phosphorylation of the $\mathrm{H} 2 \mathrm{AX}$ histone variant on a serine four residues from the carboxyl terminus is a very sensitive assay for double strand break measurements.2,14 Thirty minutes following a DNA double strand break, large numbers of $\gamma \mathrm{H} 2 \mathrm{AX}$ molecules form in the chromatin around the break site, creating a focus where proteins involved in DNA and chromatin remodeling accumulate. ${ }^{2}$ The Abrams cell lines demonstrate high levels of both double-strand DNA breaks and oxidative damage, further supporting its use as an aggressive canine OSA cell line. 
The growth of cancers is accompanied by progressive infiltration, invasion, and destruction of the surrounding tissues. Given how quickly the Abrams cell line proliferated, its ability to migrate in the Boyden chamber experiment, positive staining for alkaline phosphatase, increased numbers of double-strand DNA breaks, increased mitochondrial and nuclear oxidative damage, and lack of contact inhibition in soft agar, the Abrams line is an excellent OSA canine model, particularly metastatic OSA. Because this cancer is so devastating in the canine, further experimentations to develop therapeutic interventions would benefit veterinary medicine. Furthermore, with the myriad of similarities between species, it would be beneficial to have a working canine OSA model that could be used to further the advancement of a human cure. A comprehensive protein comparison between canine and human OSA would allow commonalities to be known and studies undertaken to alter the expression of specific proteins with the goal of tumor suppression. Evaluation of double-strand DNA breaks in spontaneously occurring canine OSA cases may provide additional clinically relevant prognostic information. Given how rapidly OSA metastasizes, and that metastatic spread greatly reduces the possibility of remission of the disease, no achievement would confer greater benefit on patients then methods to prevent the disease and/or prevent its distant spread. Currently, the inhibition of OSA metastasis, as well as the suppression of tumor growth, is still one of the most urgent issues in orthopedic oncology. Identification of canine transplantable OSA cell lines such as Abrams, are potentially useful to clarify factors that are involved in cell-to-matrix interactions as well as for analysis of the aggressive behavior and metastatic potential.

\section{Acknowledgements}

This research was funded by a College Research Council grant from the College of Veterinary Medicine and Biomedical Sciences at Colorado State University to William H. Hanneman. The authors gratefully acknowledge Mrs. Laura Chubb for her technical assistance with the alkaline phosphatase staining.

\section{Conflict of Interest}

The authors have declared that no conflict of interest exists.

\section{References}

1. Boston SE, Ehrhart NP, Dernell WS, Lafferty M, Withrow SJ: Evaluation of survival time in dogs with stage III osteosarcoma that undergo treatment: 90 cases (1985-2004). J Am Vet Med Assoc 2006;228(12):1905-8
2. Bonner WM, Redon CE, Dickey JS, Nakamura AJ, Swedelnikova OA, Solier S, Pommier Y: gammaH2AX and cancer. Nat Rev Cancer 2008;8(12): 957-967

3. Bretaud S, Allen C, Ingham PW, Bandmann O: p53-dependent neuronal cell death in a DJ-1-deficient zebrafish model of Parkinson's disease. J Neurochem 2007;100(6):1626-35

4. Chen HC: Boyden chamber assay. Methods Mol Biol 2005;294:15-22

5. Chun R, Garrett LD, Henry C, Wall M, Smith A, Azene NM: Toxicity and efficacy of cisplatin and doxorubicin combination chemotherapy for the treatment of canine osteosarcoma. J Am Anim Hosp Assoc 2005;41(6):382-7

6. DeMaria R, Miretti S, Lussich S, Olivero M, Morello E, Bertotti A, Christensen JG, Biolatti B, Levine RA, Buracco P, DiRenzo ME: met oncogene activation qualifies spontaneous canine osteosarcoma as a suitable pre-clinical model of human osteosarcoma. J Pathol 2009;18(3):399-408

7. Ehrhart N, Dernell WS, Hoffman WE, Weigel RM, Powers BE, Withrow SJ: Prognostic importance of alkaline phosphatase activity in serum from dogs with appendicular osteosarcoma: 75 cases (1990-1996). J Am Vet Med Assoc 1998;213(7):1002-6

8. Fan J, Ren H, Jia N, Fei E, Zhou T, Jiang P, Wu M, Wang G: DJ-1 Decreases Bax Expression through Repressing p53 Transcriptional Activity. J Biol Chem 2008;283(7):4022-30

9. Fitzpatrick CL, Farese JP, Milner RJ, Salute ME, Rajon DA, Morris CG, Bova FJ, Lurie DM, Siemann DW: Intrinsic radiosensitivity and repair of sublethal radiation-induced damage in canine osteosarcoma cell lines. Am J Vet Res 2008;69(9):1197-202

10. Flint AF, U'Ren L, Legare ME, Withrow SJ, Dernell W, Hanneman WH: Overexpression of the erbB-2 proto-oncogene in canine osteosarcoma cell lines and tumors. Vet Pathol 2004;41(3):291-6

11. Garzotto CK, Berg J, Hoffman WE, Rand WM: Prognostic significance of serum alkaline phosphatase activity in canine appendicular osteosarcoma. J Vet Intern Med 2000;14(6):587-92

12. Goorin AM, Abelson HT, and Frei E 3rd: Osteosarcoma: fifteen years later. N Engl J Med 1985;313(26):1637-43

13. Kanaya N, Yazawa M, Goto-Koshino Y, Mochizuki M, Nishimura R, Ohno K, Sasaki N, Tsujimoto H: Anti-tumor effect of adenoviral vector-mediated p53 gene transfer on the growth of canine osteosarcoma xenografts in nude mice. J Vet Med Sci 2011; [Epub ahead of print].

14. Kato TA, Okayasu R, Bedford JS: Signatures of DNA double strand breaks produced in irradiated G1 and G2 cells persist into mitosis. J Cell Physiol 2009;219(3): 760-765

15. Levine RA, Fleischli MA: Inactivation of p53 and retinoblastoma family pathways in canine osteosarcoma cell lines. Vet Pathol 2000;37(1):54-61.

16. Levine RA, Forest $T$, Smith C: Tumor suppressor PTEN is mutated in canine osteosarcoma cell lines and tumors. Vet Pathol 2002;39(3):372-8

17. Levine RA: Overexpression of the sis oncogene in a canine osteosarcoma cell line. Vet Pathol 2002;39(3):411-2

18. Liptak JM, Dernell WS, Straw RC, Rizzo SA, Lafferty MH, Withrow SJ: Proximal radial and distal humeral osteosarcoma in 12 dogs. J Am Anim Hosp Assoc 2004;40(6):461-7

19. Mueller F, Fuchs B, and Kaser-Hotz B: Comparative biology of human and canine osteosarcoma. Anticancer Res , 2007;27(1A): 155-64.

20. Stokkel MP, Linthorst MF, Borm JJ, Taminiau AH, Paviuels EK: A reassessemtn of bone scintigraphy and commonly tested pretreatment biochemical parameters in newly diagnosed osteosarcoma. J Canc Res Clin Oncol 2002;128(7):393-9

21. Tomer G, Cohen IJ, Kidron D, Katz K, Yosipavitch Z, Meller I, Zaizov R: Prognostic factors in non-metastatic limb osteosarcoma. Int J Oncol 1999;15(1):179-85 
22. Vander Griend RA: Osteosarcoma and its variants. Orthop Clin North Am 1996;27(3):575-81

23. Withrow SJ, Liptak JM, Straw RC, Dernell WS, Jameson VJ, Powers BE, Johnson JL, Brekke JH, Douple EB: Biodegradable cisplatin polymer in limb-sparing surgery for canine osteosarcoma. Ann Surg Oncol 2004;11(7):705-13

24. Withrow SJ, Powers BE, Straw RC, Wilkins RM: Comparative aspects of osteosarcoma. Dog versus man. Clin Orthop Relat Res 1991; (270):159-68 